\title{
Compiling Textbook of Elastic-plastic Mechanics for Major of Oil and Gas Storage and Transportation Engineering
}

\section{Yanfei Chen* Yufeng Yan Heng Ni Mingchang He Zhihao Wang Zuming Wu}

National Engineering Laboratory for Pipeline Safety/MOE Key Laboratory of Petroleum Engineering/Beijing Key Laboratory of Urban Oil and Gas Distribution Technology, China University of Petroleum (Beijing), Beijing, 102249, China

\section{ARTICLE INFO}

Article history

Received: 7 October 2021

Revised: 14 Octoberr 2021

Accepted: 20 October 2021

Published Online: 30 October 2021

Keywords:

Petroleum colleges and universities

Elastic-plastic mechanics

Textbook construction

Graduate education

\begin{abstract}
"Elastic-plastic mechanics" is a required course for engineering postgraduates in petroleum colleges and universities, such as students who major in oil and gas storage and transportation engineering. It is the basis for personnel engaged in structural safety assessment. In the past teaching process, the teaching effects of this course were unsatisfactory. There are many reasons for this phenomenon, such as the strong theoretical nature of this course, the need for a large number of formula derivation, the high requirements for students' mechanical foundation and mathematical foundation, the lack of appropriate teaching materials and the slackness of students' minds. Based on years of teaching experience, the teaching team has reformed the existing teaching materials of "Elastic-plastic mechanics" to meet the needs of petroleum colleges and universities. In this reform, we have referred to a large number of published textbooks of "Elasticplastic mechanics" and the experience of textbook construction at home and abroad. The newly compiled textbook of "Elastic-plastic mechanics" plays a certain role in improving the teaching quality of "Elastic-plastic mechanics" in petroleum colleges and universities.
\end{abstract}

innovating technology, with new ideas and technologies emerging one after another. In the face of such great changes, it is a serious problem for Petroleum Colleges and Universities to improve students' competitiveness and cultivate innovative and research-oriented talents to meet the needs of enterprise development. As one of the "double first-class" universities, China University of Petroleum (Beijing) has always upheld the idea that graduate education is the concentrated embodiment of national talent competition, scientific and technological competition, and one of the core elements of building an innovative country ${ }^{[7]}$. In recent years, with the rapid increase in the scale and growth rate of graduate students

*Corresponding Author:

Yanfei Chen,

National Engineering Laboratory for Pipeline Safety/MOE Key Laboratory of Petroleum Engineering/Beijing Key Laboratory of Urban Oil and Gas Distribution Technology, China University of Petroleum (Beijing), Beijing, 102249, China;

Email: chenyfvip@163.com 
in China, many problems have emerged in graduate education, such as quality decline, lack of innovation and disconnection between teaching and engineering practice ${ }^{[8,9]}$. Accordingly, the teaching team of the safety course of oil and gas storage and transportation engineering major carried out investigation and research on the teaching situation and effects of several courses, and actively carried out the reform and exploration of teaching materials to improve the teaching quality.

As the carrier of petroleum, natural gas and other fossil fuel transportation, the strength of oil and gas pipelines are very important. In view of the frequent occurrence of oil and gas pipeline leakage, explosions and other safety accidents at home and abroad, oil and gas storage and transportation engineering safety courses have been paid more and more attention by petroleum universities. As an extension of engineering mechanics, elastic-plastic mechanics is an essential part of the knowledge structure of higher engineering talents. It is an important basic theoretical course for graduate students majoring in oil and gas storage and transportation engineering, safety science and engineering, offshore oil and gas engineering and mechanical engineering in petroleum universities. It provides important theoretical support for students to learn finite element methods, pipeline structure design and other courses, as well as scientific research in the field of pipeline strength assessment. Elastic-plastic mechanics is an important branch of solid mechanics, which is specialized in studying the stress, strain, displacement and their distribution laws of deformable solid under the influence of external factors. Based on the assumption of continuity, uniformity, isotropy, small deformation and no initial stress, starting from statics, geometry and physics, and through a series of rigorous mathematical derivation, the basic equations such as equilibrium equation, geometric equation and physical equation are obtained as the basis for solving the problems of elasticplastic mechanics ${ }^{[10-12]}$. It can be seen that "Elastic-plastic mechanics" is a theoretical course, which needs a solid foundation in mathematics and mechanics. In the past teaching process, the learning materials of our students in learning this course are mainly PPT used by teachers in class, supplemented by books related to elastic mechanics, plastic mechanics and elastic-plastic mechanics published by relevant experts such as Yang Guitong, $\mathrm{Xu}$ Zhilun and $\mathrm{Xu}$ bingye. Although these materials have their own merits, they are generally theoretical and not closely combined with engineering (especially Oil and Gas Engineering). In addition, students generally have a bad impression of "not understanding in class and not doing homework after class" in mechanics courses and they usually have their own scientific research tasks. As a result, the teaching effects of this course are not satisfactory. In view of this situation, the teaching team first carried out a series of investigations and found that most of the domestic mechanics textbooks borrowed from the textbooks of Britain, America and the Soviet Union at the beginning. After more than 60 years of construction, many high-quality textbooks such as curriculum textbooks for the 21 st century and national planning textbooks from the tenth five-year plan to the 13th five-year plan have emerged. Even so, the construction of mechanics textbooks in China still lags behind the development of science and technology, can not keep up with the pace of the development of the times, and can not form a highlevel mechanics textbook system with the characteristics of the times ${ }^{[13]}$.

Based on the poor teaching effects of "Elastic-plastic mechanics" and the insufficient construction of domestic mechanics teaching materials and graduate teaching materials, the teaching team reviewed the teaching content of this course in combination with the advantages of excellent published textbooks on elastic-plastic mechanics at home and abroad, taking into account the students' mastery of their own mechanics foundation, and compiled the textbook of elastic-plastic mechanics for Petroleum Colleges and Universities - Basic Theory and Engineering Application of Elastic-plastic Mechanics ${ }^{[14]}$.

\section{Exploration and Attempt of Textbook Reform}

Graduate education is very different from any form of education that students have received before. This stage is the golden period for students to change from receptive learning to research-based and autonomous learning ${ }^{[15]}$. In order to cultivate the research ability of students engaged in structural analysis and help them learn the course of "Elastic-plastic mechanics" well, the teaching team integrated the existing teaching and scientific research materials, compiled elastic-plastic mechanics textbooks suitable for graduate students in Petroleum Colleges and universities, and achieved some results.

\subsection{Pay Attention to Basic Knowledge Explanation}

For engineering graduate students in colleges and universities with obvious industry characteristics, such as petroleum colleges and universities, the foundation of mechanics and mathematics is generally weak. Even some interdisciplinary graduate students have not studied mechanics subjects such as statics and material mechanics during their undergraduate years. This not only makes it 
more difficult for students to learn the course, but also for teachers to teach the course. Therefore, the teaching team pays special attention to the explanation of basic knowledge when compiling teaching materials.

The textbook consists of 12 chapters, which can be roughly divided into three parts: explanation of basic theoretical knowledge, solution of elastic-plastic mechanics in both the rectangular coordinate system and polar coordinate system, and solution of specific elastic-plastic mechanics problems. As the cornerstone of the whole elastic-plastic mechanics, the basic theory accounts for more than one third of the space. The students are introduced in detail and systematically to the contents of stress analysis, strain analysis, elasticplastic constitutive relationships and yield criterions. As a course with strong theoretical derivation, formula derivation is essential. This part is also one of the most difficult parts for students in the past teaching process. This is because in the process of deriving formulas, once some intermediate derivation steps are skipped, they will not form a complete knowledge chain and lose interest in the following learning. So, in the process of textbook compilation, we give detailed derivation steps as much as possible. For example, when solving the elastic-plastic mechanical problem of thick-walled cylinders with displacement solution, the equilibrium equation expressed by displacement component is $\frac{\mathrm{d}^{2} u}{\mathrm{~d} r^{2}}+\frac{1}{r} \frac{\mathrm{d} u}{\mathrm{~d} r}-\frac{u}{r^{2}}=0$. The formula needs to be deformed in the process of solving specific problems. In the common textbook of "Elasticplastic mechanics", the final result will be directly given as $\frac{\mathrm{d}}{\mathrm{d} r}\left[\frac{1}{r} \frac{\mathrm{d}(r u)}{\mathrm{d} r}\right]=0$. This is difficult for students who are not very good at mathematics. In this textbook reform attempt, in order to make it easier for students to master the knowledge, we give the detailed derivation steps of this result, that is $\frac{\mathrm{d}^{2} u}{\mathrm{~d} r^{2}}+\frac{1}{r} \frac{\mathrm{d} u}{\mathrm{~d} r}-\frac{u}{r^{2}}=0 \Leftrightarrow \frac{\mathrm{d}}{\mathrm{d} r}\left(\frac{u}{r}+\frac{\mathrm{d} u}{\mathrm{~d} r}\right)=0$, $\frac{u}{r}+\frac{\mathrm{d} u}{\mathrm{~d} r}=\frac{1}{r} \frac{\mathrm{d}(r u)}{\mathrm{d} r}$. Examples like this can be seen everywhere in this textbook to help students easily master the derivation process. In the process of using the textbook, through interview and investigation, many students think that the derivation process is not as difficult as expected.

\subsection{Closely Combined with the Characteristics of the Petroleum Industry}

As a basic subject of engineering technology, "Elasticplastic mechanics" is a required course for many science and engineering majors, such as civil engineering, safety engineering, marine engineering, etc. It is valued by colleges and universities. In order to meet the needs of all schools, the focus of elastic-plastic mechanics textbooks on the market is not very prominent. Thus, these textbooks generally include the elastic-plastic analysis of members, the elastic-plastic analysis of rectangular section beams, the elastic-plastic analysis of thick-walled cylinders, the elastic-plastic analysis of rotating disks, the bending of plates and the ultimate bearing capacity analysis of geotechnical structures and so on. For the oil industry, it has obvious industrial characteristics. Most of the common structures in oil and gas engineering are cylindrical. For example, the sucker rod used in drilling engineering, the oil and gas transmission pipeline used in oil and gas gathering and long-distance transmission, and the oil storage tank for storing crude oil and product oil in the oil depot are cylindrical structures. In the elasticplastic analysis of cylindrical objects, if the rectangular coordinate system is still used, it is difficult to clearly describe the boundary conditions and other related problems. At this time, if the polar coordinate system is used to solve the problem, the boundary conditions will be presented in a very simple form, which will greatly simplify the solution of elastic-plastic problems of cylindrical structures. Therefore, when compiling this textbook, the teaching team focused on the polar coordinate solution of plane problems, elastic-plastic analysis of thick wall cylinders and other contents closely combined with the petroleum industry. The contents that are not closely related to the oil industry are appropriately simplified.

\subsection{Rich Examples to Consolidate Learning Achievements}

Only by theoretical teaching, students can never master relevant knowledge, let alone a highly theoretical course such as "Elastic-plastic mechanics". In addition to classroom teaching, doing a lot of exercises is also a necessary way to master relevant knowledge. For students who are beginning to learn elastic-plastic mechanics, it is not practical to do exercises with the just learned theory at the beginning. Moreover, for engineering students, learning this theoretical knowledge is to solve practical engineering problems. Thus, we have specially selected a large number of practical examples related to oil and gas storage and transportation engineering to provide students with problem-solving ideas. For example, when analyzing the elastic-plastic problems of thick-walled cylinders, the common textbooks basically analyze the distribution of stress, strain and displacement of thick 
walled cylinders under uniform internal and external pressure. In practical engineering, it is more common for cylindrical pressure vessels to be subjected to nonuniform pressure, such as buried pipelines. Based on this, according to the superposition principle, the non-uniform pressure is decomposed into uniform pressure, cosine load and sinusoidal load, and then the results of elasticplastic analysis of thick wall cylinder under trigonometric function load can be obtained according to the results and inverse solution (or semi-inverse solution) of elasticplastic analysis of thick wall cylinder under uniform pressure. These examples closely combined with practical engineering problems have laid a solid theoretical foundation for students to engage in relevant work in the future.

\subsection{Keep up with the Forefront of Scientific and Technological Development}

Graduate education is closely related to the development of modern science and technology. Hence, introducing scientific research into the teaching process is the most significant difference between graduate education and other levels of education. Therefore, graduate textbooks should highlight the latest research results, research hotspots, new technologies and new methods in specific disciplines or fields at home and abroad ${ }^{[16]}$. The teaching team specially introduced the elastic-plastic analytical solution of pressure pipeline under combined load to the students according to the research trend of ultimate bearing capacity of complete pipeline and pipeline with corrosion defects at home and abroad in recent years and the achievements of the research group in these aspects. The latest research progresses on pipeline safety assessment, such as the influencing factors of ultimate bending moment of penstock under different combined loads and the analytical solution of ultimate load of pipeline with different shapes of corrosion defects under combined loads.

\subsection{Integration into Ideological and Political Education}

In recent years, with the continuous enrollment expansion of colleges and universities, the scale of students in colleges and universities has risen sharply, which leads to a dramatic decline in the quality of students. Many students don't listen to the lectures attentively, and only rely on a few nights before the exam to complete a semester of course learning tasks. In addition, for most graduate students, they will publish some papers in some journals and magazines. Especially when they graduate, they are also required to write graduation papers. In recent years, academic misconduct such as paper fraud and plagiarism have often been exposed, which has a very bad social impact. All these reflect that it is urgent for colleges and universities to carry out ideological education for students. In 2020, the Ministry of Education issued the "Guideline for the Ideological and Political Construction of Higher Education Curriculum", which requires schools to integrate ideological and political education into the talent training system. In particular, it is necessary to comprehensively carry out the reform of ideological and political education in higher education and improve the talent training quality in all aspects. In order to solve the fundamental problems of talent training of "what kind of people to train", "how to train people" and "for whom to train people", the teaching team specially selected 12 outstanding scientists who have made outstanding contributions to New China in the fields of physics and mechanics, such as Qian Xuesen, Qian Sanqiang, Deng Jiaxian, Li Siguang and Yu Min, to tell the students about their full enthusiasm for learning, rigorous scientific attitude and full of patriotism, so as to encourage students to work hard and make achievements in the future to serve the motherland.

\section{Conclusions}

"Elastic-plastic mechanics" is an important basic course for graduate students, and it is an indispensable part of oil and gas storage and transportation safety courses. In view of the current teaching situation, industry characteristics and teaching materials, the teaching team has carried out exploration on teaching materials construction mainly from the aspects of basic knowledge, industry characteristics, engineering examples, scientific and technological frontier and ideological and political education, so as to improve the teaching quality of this course. The results obtained have made some achievements in graduate classroom teaching practice, and also provided a direction for how to help students master this course in the future.

\section{Acknowledgements}

The work was financially supported by: China University of Petroleum (Beijing) Postgraduate Key Educational Reform Project "Construction of the textbook Basic Theory and Engineering Application of Elastic-plastic Mechanics combined with the oil and gas industry".

\section{References}

[1] Hu W R, Bao J W. Development Trend of Petroleum 
Industry and Countermeasures of China[J]. Journal of China University of Petroleum (Edition of Natural Science), 2018, 42 (04): 1-10.

[2] $\mathrm{Hu}$ W R. A New Understanding of Petroleum: Oil Attractiveness is Gradually Fading[M]. Beijing: Petroleum Industry Press House, 2018.

[3] Ma S P. The cause of the decline in international oil prices and their impact on the Chinese economy[J]. Academic Exchange, 2015 (03): 143-147.

[4] Luo Z X, Zhou X K, Lu X M. Oil companies' operating strategies under low oil prices[J]. International Petroleum Economy, 2015, 23 (04): 51-58 + 111.

[5] Zeng X Q. Response to market challenges under low oil price of China's petroleum and petrochemical enterprises $[\mathrm{J}]$. International Petroleum Economy, 2015, 23 (12): 1-9.

[6] Feng Q H, Wei Y G, Zheng D P, et al. Domestic and international oil companies' practices under low oil price and its enlightenment $[\mathrm{J}]$. International Petroleum Economy, 2016, 24 (07): 39-43.

[7] Liu Y X, Yao W L, Chen J, Zheng Y R. Constructing the "Innovation" Gene and Improving the Postgraduate Textbook of "Plastic Mechanics of Geomaterial "[J]. Research in Higher Education of Engineering, 2021 (05): 100-105.

[8] China Education Online. 2021 National Postgraduate Enrollment Survey Report [EB/OL]. https://www.eol. cn/e_ky/zt/report/2021/catalog.html.
[9] Liu G H, Meng Z H. On the Development Logics of Postgraduate Education[J]. Educational Research, 2015, 36 (01): 66-74.

[10] Liu P, Zhou G B, Sun K. Teaching Reform of the Elastic-plastic Mechanics in Graduate Students[J]. Education Modernization, 2019, 6 (18): 44-46.

[11] Hou Z F. The Teaching Innovation of Elasticity in a Popular Education[J]. Science and Technology of West China, 2009, 8 (26): 75-76.

[12] Lou W J, Liang H C, Yang L X. Discussion on Teaching Method Improvement in the Course of Elasticity[J]. Higher Education Forum, 2015 (07): 40-44.

[13] Ye Z M, Li J F, Wang S B, et al. On Teaching System Investigation to the Textbooks of Elementary Mechanics(I)—A brief Introduction on the Elementary Mechanics Textbooks Published Within China[J]. Mechanics in Engineering, 2019, 41 (03): 314-319.

[14] Li Y L, Sun R, Wei Q Y. A Comparative Study of Chinese and Foreign Postgraduate Textbooks of Mechanical Engineering $[\mathrm{J}]$. Journal of Graduate Education, 2011 (06): 35-40.

[15] Mao J H. Teaching for Thinking: on Postgraduate Curriculum "Golden Course" Construction[J]. Journal of Graduate Education, 2019 (03): 60-65.

[16] Sun Y, Chen L X, Wang C. International Experience and China Path of Graduate textbook Construction[J]. Academic Degrees \& Graduate Education, 2018 (02): 72-77. 